\title{
Endoscopic Evaluation of Upper Airway While Playing the Didgeridoo
}

\author{
Peter Michael Baptista ${ }^{1}$, Rodolfo Lugo-Saldaña ${ }^{2}$, Octavio Garaycochea ${ }^{1 *}$ \\ ${ }^{1}$ Department of Otorhinolaryngology, Clínica Universidad de Navarra, University of Navarra, Avenida Pío XII 36, 31008 Pamplona, Spain \\ ${ }^{2}$ Otorrinolaringología Clínica Hospital Constitución ISSSTE. Monterrey, Mexico
}

Submission: April 10, 2017; Published: April 19, 2017

*Corresponding author: Octavio Garaycochea, Department of Otorhinolaryngology, Clínica Universidad de Navarra, University of Navarra, AvenidaPío XII 36, 31008 Pamplona, Spain, Europe, Email: ogaraycoche@unav.es

\begin{abstract}
Obstructive sleep apnea (OSA) is a common disorder caused by not only an impaired upper airway anatomy (i.e. anatomically narrow/ collapsible airway), but also by several non-anatomical factors. There are diverse types of treatments. Upper airway stimulation associated with the playing of specific musical instruments may provide an effective alternative method of treatment for persons diagnosed with OSA, particularly those with mild to moderate forms of OSA, for which CPAP may be ineffective or inappropriate. We have performed an endoscopic view of the upper airway can be seen while a musician is playing the didgeridoo, performing circular breathing. To our knowledge this is the first paper showing how a rhythmic sound is achieved through the movements of the lateral walls and of the soft palate, and muscles of the tongue, cheeks and lips that can be seen in the video.
\end{abstract}

Keywords: Obstructive Sleep Apnoea; Upper airway; Endoscopy; Didgeridoo

Abbreviations: OSA: Obstructive Sleep Apnea; SDB: Sleep-Disordered Breathing; MCI: Mild Cognitive Impairment; UA: Upper Airway; CPAP: Continuous Positive Airway Pressure; AASM: American Academy of Sleep Medicine; TMJ: Temporo-Mandibular Joint dysfunction; EMG: Electromyography

\section{Introduction}

Snoring has been long considered a social nuisance that is very common with important sociable repercussion. It is caused by the vibration of the structures in the oral cavity and oropharynx, namely the soft palate, uvula, tonsils, base of tongue, epiglottis, and pharyngeal walls. It has been related to Obstructive sleep apnea (OSA), in which a partial or complete collapse of the upper airway takes place in those same structures mention before. OSA is a common sleep disorder. Young et al. [1] studied 602 state employees with attended overnight polysomnography and found that the incidence of sleep-disordered breathing (SDB) was $24 \%$ in men and $9 \%$ in women [1]. Most of these patients are undiagnosed and systematic reviews of evidence confirms that advancing age, male sex, and higher body-mass index increase OSA prevalence [2,3].

OSA has been associated with many chronic diseases including hypertension myocardial infarction, stroke, insulin resistance, diabetes, nonalcoholic fatty liver disease, and most recently mild cognitive impairment (MCI)/dementia/ depression and cancer [4]. Compromised sleep has also been identified as a risk factor for driving accidents [5] deteriorated quality of life, and increased health-care costs [6]. The pathogenesis of OSA is multifactorial. Recent advances in the understanding of OSA pathogenesis have shed new light on the heterogeneity of this disorder. Interactions between the primary cause of OSA, impaired upper airway (UA) anatomy (i.e. anatomically narrow/ collapsible airway) and pharyngeal dilator muscle activity have long been appreciated as key contributors to OSA pathogenesis. However, the neural control of the pharyngeal muscles and their role in contributing to OSA pathogenesis is much more complex than simply loss of muscle contractility during sleep onset.

Other non-anatomical traits or phenotypes, such as the propensity for awakening during airway narrowing (respiratory arousal threshold) and stability of the respiratory control system (loop gain), are also important contributors to OSA for 
a substantial proportion of OSA patients [7]. There is no single treatment for OSAS that is universally accepted and that has long-lasting effects. Continuous positive airway pressure (CPAP) has been recommended by the practice parameters published by the American Academy of Sleep Medicine (AASM) as first-line and gold-standard treatment. However, the AASM parameters also recognized that a significant proportion of patients are unable to tolerate CPAP therapy, and frequently seek alternate treatment [8].

Therefore, a substantial proportion of patients still remain ineffectively treated by it. It is also associated with devicerelated complications like mask discomfort, rejection of partner, and cutaneous allergies which lead to low compliance of the patients for CPAP [8]. Weight reduction by diet or surgery does cause improvement in AHI but symptoms tend to reoccur on resumption of normal diet [9]. Intra-oral devices like lingual retainers and jaw petitioners do improve sleep disturbances in OSAS temporarily. However, it is associated with problems like use of extensive dental prosthesis, periodontal problems, and intense temporomandibular joint dysfunction (TMJ) $[10,11]$. Alternatively, various surgical techniques have been developed involving a modification of the anatomy of the upper airway, with variable results.

There have been publications suggesting the theory [9] that upper airway stimulation associated with the playing of specific musical instruments may provide an effective alternative method of treatment for persons diagnosed with OSA, particularly those with mild to moderate forms of OSA, for which CPAP may be ineffective or inappropriate [10]. A randomized trial showed that playing the didgeridoo a wind instrument of the indigenous Australians was associated with a reduction in sleepdisordered breathing events and daytime sleepiness. Playing the didgeridoo requires the use of circular breathing, a technique used to produce a continuous tone without break, accomplished by the use of the cheeks as a reservoir of air while breathing through the nose rather than the mouth. It has been suggested that practicing this wind instrument may train airway muscles leading to less collapse of oropharygeal muscles at night, resulting in its beneficial effect on sleep apnea. We present a video of a Didgeridoo musician playing the instrument while and endoscope is inserted through the nose into the upper airway tract. We believe that it is the first time that the movements of the oropharynx muscles are show during a recital.

\section{Material and Methods}

\section{Instrument}

The instrument was made from an Agave flower stalk that had dried out and whose interior had been eaten by termites to provide a suitable central bore. It was cut to a desired length of $1.5 \mathrm{~m}$. somewhat flared from about $50 \mathrm{~mm}$ at the blowing end to about to $150 \mathrm{~mm}$ at the open end.

\section{Player}

Didgeridoo musician/professor (Luis Mendez,see acknowledgement for details) who had been playing the Australian origin instrument for the past 12 years, practicing in a daily routine for a period of approximately 6 hours a day. During one of his presentations and after is voluntary consent we informed him of our interest to record his performance through and endoscopic view. The ENTityXLNaso View Nasopharyngoscope with an integrated LED light source provided visibility of the nose and pharynx coupled to an Iphone 6 through Clear scope adaptor for Mobile endoscopic video with the Modica phone application. The endoscope was introduced through the nose towards the pharynx while the musician performed his Didgeridoo recital for a period of approximately 5 minutes. The musician was able to perform circular breathing and diverse sounds without major inconvenience. The musician was recorded and a segment of the recording has been inserted in this article to show evidence of our novel description (Video 1).

\section{Results}

In the video a rhythmic sound is achieved through the movements of the lateral walls and of the soft palate, and muscles of the tongue, cheeks and lips. The vibrating lips generate a sound signal that is transmitted both into the instrument and into the mouth. A clear lateral movement of closure of the airway at the level of nasopharynx and oropharynx is achieved with the palatopharyngeal muscles at each side and antero-posterior closure and opening through the movement of the soft palate with the levatorveli palatini and tensiveli palatini muscles. Palatopharyngeal muscles seem to bulge in, and enlarge their volume many times closing laterally the oropharyngeal wall. Enlargement and tension of the palate surface tends to close and open the antero-posterior surface allowing flow of air and creation of diverse sounds, in spectacular, rhythmic variations in timbre, which are produced by the player's vocal tract.

\section{Discussion}

Sleep in patients with OSA is accompanied by decreases in 
neuromuscular activity of muscles, which dilate and stiffen the pharyngeal airway during inspiration. Interestingly, an increase in muscle activity, presumably compensatory in nature, occurs in these patients during wakefulness. Changes in morphology and proportion of fibber type consistent with muscle injury have been observed in the upper airway dilator muscles, both in animal models of OSA and in OSA patients [11]. It has been shown that training of the tongue muscles by electrostimulation was effective in reducing snoring in OSA patients. A significant reduction in symptoms and overall severity was demonstrated in patients with moderate OSA following an extensive oropharyngeal exercise program, derived from speech therapy. Thus, both electrical and physical stimulation (via exercise) may have beneficial consequences and contribute to proper maintenance of upper airway patency.

Oropharyngeal exercises have been described as a noninvasive, cost-effective treatment which acts by increasing the tone of pharyngeal muscles. It aims at correcting the posture adequacy, the sensibility and proprioception, and the to- nus and mobility of the orofacial and pharyngeal musculature. The exercises reinforce the oropharyngeal muscles and increase their tone, thereby dilating the upper airways during sleep. Verman RK et al. [12] described their results of oropharyngeal exercises which caused a significant reduction of neck circumference, with an improvement of symptoms like daytime sleepiness, witnessed apnea, and snoring intensity, with a significant improvement in sleep indices like minimum oxygen saturation, Sao2 < $90 \%$, sleep efficiency, arousal index, and total sleep time N3 stage of sleep. Concluding a subjective improvement of OSA symptoms and theirpolysomnographic abnormalities in patients with mild to moderate OSAS.

The didgeridoo produces a continuous drone that a skilful player can modulate to produce a variety of complex rhythmic effects [13] and even achieve melodic enhancements performed through movements for the lips, tongue, cheeks, pharyngeal and laryngeal muscles. These muscles involved in the upper airway movement seem to have an important effect during sleep in patients suffering from OSA. A randomized trial showed that playing the didgeridoo, a wind instrument of the indigenous Australians, was associated with a reduction in sleep-disordered breathing events and daytime sleepiness [9].

Achieving an endoscopic evaluation during performance of the air wind instrument using circular breathing is an important aspect that has been seldom described visually. Our paper describes the lateral and antero-posterior aspects of closure of the naso-oropharynx area during performance of the didgeridoo instrument. The performer plays using the air in the inflated cheeks, with his mouth sealed from the lower vocal tract with the soft palate. This radical change in the vocal tract geometry makes a substantial change in the timbre and the necessity of frequent inhalation means that the change occurs often in continuous playing. Idiomatic playing makes a virtue of this necessity, so that the sound produced using the cheeks as reservoir is made an integral element of the rhythmic structure. Many of the rhythms used require simple alternation of inhalation and exhalation through the instrument, and this is performed graciously by an interaction of muscles in the area. A full description of the movement can be described by electromyography but is seldom seen by the observer or the performer.

We describe the use of these important muscle variations while the musician is performing. We can see how an almost complete closure and opening of the naso-oropharyngeal area is achieved in a constant, coordinated dynamic way with movement occurring at all levels and in all directions. Muscle enlargement and reduction is clearly obvious producing tension and relaxation of the airway walls. Palatal movement produces changes in tones, pitch and introduction of air from the nostril towards the rest of the airway. We believe that achieving a better view of the airway at diverse levels coupled with other parameters as Electromyography (EMG), may accomplish rehabilitation of a specific group of muscles of the airway that are contributing to airway collapse.

We are conscious of the limitations of the study in which the endoscope has only been introduced to one didgeridoo performer, not been able to study if performance of muscles may change according to the musician, gender, level of expertise, years of training or anatomic configuration and also type or length of the instrument. And also it might be useful to know if these musicians really do have less likelihood of airway collapse during sleep that might produce OSA. There have been very few papers written related to this matter. Brown et al. [14] performed an anonymous internet-based survey of professional orchestra members assessing risk of sleep apnea using the Berlin questionnaire. Wind players were more likely than nonwind players to be at high risk in unadjusted analysis (Odds ratio $=1.47,95 \% \operatorname{CI} 1.13,1.91)$, though this association was not significant in adjusted analysis (Odds ratio $=1.12(0.82,1.54)$ ). Although Polisomnogram or Polygraphy were not used.

Wardrop et al. [15] demonstrated no significant difference between the snoring severity or daytime sleepiness of brass / wind players and other professional orchestral musicians although in a questionnaire-based observational study. While the properties and structure of the pharyngeal muscles are different in severe OSA patients compared with snorers and controls [16] the extent to which these changes are acquired or inherited and their function role in OSA pathogenesis are unclear.

There is substantial heterogeneity and overlap in the pathological traits across different severities of OSA [17]. The relative contribution of each trait varies both between patients and within different severities of disease. Compared with patients with severe OSA, patients with mild OSA tend to have less collapsible airways, different sites of collapse and more abnormalities in several non-anatomical traits (e.g. high 
loop gain and low arousal thresholds). While current evidence does not point towards a difference in muscle responsiveness between patients of differing OSA severities, it appears likely that the effectiveness of a given level of muscle contraction differs between patients with mild and severe OSA although this requires further investigation [18]. For patients with mildto-moderate collapsibility, the non-anatomical traits tend to function more as 'effect modifiers' that dictate whether an individual develops OSA. Oropahryngeal exercise with the use of instruments like the Didgeridoo or other oral exercises may improve patients with mild or moderate OSA, the reason is still not clear.

\section{Conclusion}

We present a novel endoscopic view of a performance of a Didgeridoo musician while playing his instrument with circular breathing. Movement of multiple muscles can be seen with important changes in lateral pharyngeal and palatal walls. Exercise of the muscles may be the clue to improving or avoiding collapse during sleep in patients with Obstructive sleep apnea (OSA).

\section{Acknowledgment}

Luis Mendez "Independent Investigator of the therapeutic benefits of Didgeridoo" Email: sonocosmo@hotmail.com

\section{References}

1. Young T, Palta M, Dempsey J, Skatrud J, Weber S, et al. (1993) The occurrence of SDB among middle-aged adults. N Engl J Med 328(17): $1230-1235$.

2. Peppard PE, Young T, Barnet JH, Palta M, Hagen EW, et al. (2013) Increased prevalence of sleep-disordered breathing in adults. Am J Epidemiol 177(9): 1006-1014.

3. Senaratna CV, Perret JL, Lodge CJ, Lowe AJ, Campbell BE, et al. (2016) Prevalence of obstructive sleep apnea in the general population: A systematic review. Sleep Med Rev S1087-0792(16): 30064-30068.

4. Lim DC, Pack AI (2017) Obstructive Sleep Apnea: Update and Future. Annu Rev Med 68: 99-112.

5. Garbarino S, Guglielmi O, Sanna A, Mancardi GL, Magnavita N (2016)
Risk of Occupational Accidents in Workers with Obstructive Sleep Apnea: Systematic Review and Meta-analysis. Sleep 39(6): 1211-1218.

6. Watson NF (2016) Health Care Savings: The Economic Value of Diagnostic and Therapeutic Care for Obstructive Sleep Apnea. J Clin Sleep Med 12(8): 1075-1077.

7. Edwards BA, Eckert DJ, Jordan AS (2016) Obstructive sleep apnea pathogenesis from mild to severe: Is it all the same? Respirology 22(1): 33-42.

8. Rotenberg BW, Murariu D, Pang KP (2016) Trends in CPAP adherence over twenty years of data collection: a flattened curve. J Otolaryngol Head NeckSurg 45: 43.

9. Janney CA, Kilbourne AM, Germain A, Lai Z, Hoerster KD, et al. (2016) The Influence of Sleep Disordered Breathing on Weight Loss in a National Weight Management Program. Sleep 39(1): 59-65.

10. Puhan MA, Suarez A, Lo Cascio C, Zahan A, Heitz M, et al. (2006) Didgeridoo playing as alternative treatment for obstructive sleep apnoea syndrome: randomized controlled trial. BMJ 332: 266-270.

11. Serra-Torres S, Bellot-Arcís C, Montiel-Company JM, Marco-Algarra J, Almerich-Silla JM (2016) Effectiveness of mandibular advancement appliances in treating obstructive sleep apnea syndrome: A systematic review. Laryngoscope 126(2): 507-514.

12. Verma RK, Johnson JR, Goyal M, Banumathy N, Goswami U, et al. (2016) Oropharyngeal exercises in the treatment of obstructive sleep apnea: our experience. Sleep Breath 20(4): 1193-1201.

13. Tarnopolsky AZ, Fletcher NH, Hollenberg LC, Lange BD, Smith J, et al. (2006) Vocal tract resonances and the sound of the Australian didjeridu (yidaki) I. Experiment. J Acoust Soc Am 119(2): 1194-1204.

14. Brown DL, Zahuranec DB, Majersik JJ, Wren PA, Gruis KL, et al. (2009) Risk of sleep apnea in orchestra members. Sleep Med 10(6): 657-660.

15. Wardrop PJ, Ravichandran S, Hair M, Robertson SM, Sword D (2011) Do wind and brass players snore less? A cross sectional study of snoring and daytime fatigue in professional orchestral musicians. Clin Otolaryngol 36(2): 134-138.

16. Saboisky JP, Butler JE, Gandevia SC, Eckert DJ (2012) Functional role of neural injury in obstructive sleep apnea. Front Neurol 3: 95.

17. Edwards BA, Eckert DJ, Jordan AS (2017) Obstructive sleep apnoea pathogenesis from mild to severe: Is it all the same? Respirology 22(1): 33-42.

18. Owens RL, Edwards BA, Eckert DJ, Jordan AS, Sands SA, et al. (2014) An integrative model of physiological traits can be used to predict obstructive sleep apnea and response to non-positive airway pressure

\section{Your next submission with Juniper Publishers will reach you the below assets}

- Quality Editorial service

- Swift Peer Review

- Reprints availability

- E-prints Service

- Manuscript Podcast for convenient understanding

- Global attainment for your research

- Manuscript accessibility in different formats ( Pdf, E-pub, Full Text, Audio)

- Unceasing customer service

Track the below URL for one-step submission https://juniperpublishers.com/online-submission.php 